\title{
Master in "Clinical Bioethics Consultation": an Italian training program for Clinical Ethics Consultants
}

\author{
Federico Nicoli ${ }^{1} \cdot$ Renzo Pegoraro $^{2}$. \\ Antonio G. Spagnolo ${ }^{3} \cdot$ Mario Picozzi $^{1}$
}

Published online: 13 July 2016

C) Springer International Publishing AG 2016

\begin{abstract}
A Second level Master in "Clinical Bioethics Consultation" has been organized in Italy to offer an opportunity to offer an adequate training to carry out an ethics consultation in different health fields. The master has been promoted and realized by different institutions: Catholic University of Sacred Hearth in Rome, Insubria University in Varese, "Federico II" University in Naples, Lanza Foundation in Padua and the Local Health and Social Care Unit n.7 (ULSS) in Veneto Region. The aim of the master is train ethics consultants to offer help regarding a correct decision, which will take by others. The choice must be as much as possible shared between patient, family and health care team. Ethics consultation can be primarily request by the physicians, nurses and health care staff such as support about a choice that wants to be the most appropriate and to clarify a dilemma between different options. Secondly an ethics consultation can be demand by the patient and the family members to find a clarification about their dilemmas and future choices. Also the administrative staff could ask the consultation, when it need to better explain ad example about a specific clinical case or a question concerned the health policy.
\end{abstract}

Federico Nicoli

federico.nicoli82@gmail.com

Renzo Pegoraro

renzo.pegoraro@fondazionelanza.it

Antonio G. Spagnolo

antoniogioacchino.spagnolo@unicatt.it

Mario Picozzi

mario.picozzi@uninsubria.it

1 Center for Clinical Ethics, Biotechnology and Life Sciences Department, Insubria University, Varese, Italy

2 Lanza Foundation (Padua), Pontifical Academy for Life, Vatican City, Italy

3 Institute for Bioethics, Catholic University of the Sacred Heart, Rome, Italy 
Keywords Clinical ethics consultation - Applied ethics · Postgraduate clinical ethics education $\cdot$ Ethics competencies

\section{Introduction}

The peculiarity of Healthcare Ethics Consultation (HCEC) or Clinical Ethics Consultation (CEC) is the care of persons; in particular it "involves the identification, analysis and resolution of value conflicts or uncertainties that arise in the provision of health care in clinical setting" (Jennings 2014).

Ethics Consultation, as presented by American Society for Bioethics and Humanities, is "a set of service provided by an individual or a group in response to questions from patients, families, surrogates, healthcare professionals or other involved parties who seek to resolve uncertainty or conflict regarding value-laden concerns that emerge in health care" (American Society for Bioethics and Humanities 2011).

Professionals in clinical ethics field could have a different graduate training. They could be physicians, nurses, social workers, chaplains, administrators, lawyers, philosophers and theologians (American Society for Bioethics and Humanities 2015). Because of this it is necessary to offer an adequate training for those who are interested to improve own competencies to take on ethics consultation activity. Educating people with different backgrounds in clinical ethics could open many problems: firstly because there is not an official and shared education training program to become an ethics consultant; and secondly, because there are different position about "programs specifically relevant to ethics consultation" (American Society for Bioethics and Humanities 2015) of those who are on already involved in ethics consultation.

For these reasons both academic courses (Masters and Ph.D.) in order to obtain theoretical knowledge in bioethics (philosophical, medical, legal, theological), and internships in hospital wards in order to acquire specific practical skills and aptitudes in clinical ethics are developing in different Countries (Spike 2012; Dudzinski et al. 2013).

In Europe Clinical Ethics Consultation has been an increasing interest during the last two decades (Hurst et al. 2007), clinical ethics services are already officially operating in the Healthcare realities of many other European Countries, but in different manner (Akabayashi 2014; Gusmano et al. 2010; Pegoraro et al. 2007; Widdershoven et al. 2009; Pfäfflin et al. 2009).

Also in Italy there is no academic standard regarding the training of ethics consulting. Therefore it seems to be only during the postgraduate education that a formerly graduate person can acquire specific competences to lead an ethics consultation (in particular case for those persons that have not a graduate training concerning the healthcare).

This issue underscores the importance of defining the professional profile of the clinical ethics consultant and offering an adequate training to qualify those involved in ethics consultation (Kodish et al. 2013). For this reason it has been organized in Italy a Master oriented to offer an opportunity to improve those abilities to carry out an ethics consultation in different health fields. Second level professional Master in "Clinical Bioethics Consultation" has been carried out to train the future ethics consultants. The master has been promoted and realized by different academic and 
nonacademic institutions: the Catholic University of Sacred Hearth in Rome, the Insubria University in Varese, the "Federico II" University in Naples, the Lanza Foundation in Padua and the Local Health and Social Care Unit n.7 (ULSS) in Veneto Region (Nicoli et al. 2015).

Regular student of the Master has a Master Degree, Degree, Bachelor's Degree in different fields: Healthcare; Sciences of Life, Psychology, Law, Philosophy, Theology and Pastoral Service.

The master is also related to the national working group of Healthcare Ethics Consultation. The group began to take shape and to be organized in 2010; its activities are largely directed to share experiences, to analyze this field and to develop a professional profile of the clinical ethicist recognized throughout the nation (Pegoraro et al. 2016; Zonza and Refolo 2014). Since 2010 the newborn working group of Clinical Ethics and Healthcare Ethics Consultation has organized meetings and conferences to debate about the situation of Clinical Ethics in Italy and the ways to perform the Ethics Consultation (Pegoraro et al. 2015; Reich et al. 2003).

\section{The contents of the master in clinical ethics consultation}

Advancement of this new kind of healthcare profession is strictly related to train on specific competencies to face a lot of issue in the daily clinical practice (Agich 2013) to find a good solution on single clinical case (Zaner 1999). This set of competencies does not concern only good abilities in ethics analysis (Gligorov et al. 2015), but a set of things "including accurate factual information, effective communication skills, and the insights and contributions of a wide variety of professionals" (American Society for Bioethics and Humanities 2009). In fact, patients and physicians could arrive to different choices in similar clinical situation: the possibilities to make different choices (Niebroj 2010) are related to the fact that every medical case is original, univocal and the consciences of the protagonists could present different judgments.

For these reasons, according to the Core Competencies of the ASBH, this master is structured in three macro areas of interest: area of core knowledge, area of ethical assessment and analysis skills, area of process, evaluative, and interpersonal skills (American Society for Bioethics and Humanities 2011) (Table 1).

In the daily clinical practice every healthcare specialists are calling to respond at ethical issues, the ethics consultation "differ from other healthcare professionals in that [he/she has] been assigned by [his/her] institutions the distinctive role of responding to specific ethical concerns and questions that arise in the delivery of health care, and therefore require a distinctive set of competences to perform this role effectively" (American Society for Bioethics and Humanities 2011).

Master presents main objectives: a specific educational training to improve competencies in clinical ethics for those who should be hire in Bioethics Services or Ethics Committees (Racine and Hayes 2006); and, a set of knowledge on ethics issues that could be found in clinical setting (i.e. human experimentation, health technology assessment, and organizational issues) and how ethics consultation could resolve them.

Consequently, some specific purposes are pursued. The goal of the consultant is provide help regarding making a decision which will often involve others (Brock et al. 2014). Choices must be, as much as possible, shared among the patient, the family and the health care team. The consultant acts for the good of those requesting a consultation 
Table 1 Contents of the Master

\begin{tabular}{|c|c|c|}
\hline Area of core knowledge & $\begin{array}{l}\text { Area of ethical assessment } \\
\text { and analysis skills }\end{array}$ & $\begin{array}{l}\text { Area of process, evaluative, } \\
\text { and interpersonal skills }\end{array}$ \\
\hline $\begin{array}{l}\text { - Ethical Theory } \\
\text { - Moral Reasoning } \\
\text { - Basic Bioethical Issues } \\
\text { and Concepts } \\
\text { - Basic knowledge in Healthcare } \\
\text { systems and legislation } \\
\text { - Fundamental issues concerning } \\
\text { Medicine, Genetics } \\
\text { - Scientific elements concerning } \\
\text { the beginning of life, the end } \\
\text { of life, experimentation, } \\
\text { transplants, intensive care. }\end{array}$ & $\begin{array}{l}\text { - Identify the nature of the value } \\
\text { uncertainty or conflicts } \\
\text { - Clarify relevant ethical concepts } \\
\text { - Apply relevant ethical consideration } \\
\text { - Identify and justify a range of } \\
\text { ethically acceptable options } \\
\text { - Listen and communicate interest, } \\
\text { respect, support }\end{array}$ & $\begin{array}{l}\text { - Process skills } \\
\text { - Methods of ethics consultation } \\
\text { - Different models of HCEC } \\
\text { supports/services } \\
\text { - Enable involved parties to } \\
\text { communicate effectively } \\
\text { - Run an effective HCEC services } \\
\text { - Consultation in neonatology, } \\
\text { geriatrics, end of life issues, } \\
\text { genetics, experimentation, } \\
\text { psychiatry, technologies. }\end{array}$ \\
\hline
\end{tabular}

(Orlowski et al. 2006; Aulisio et al. 2003). The single clinical case is the starting point of the ethics consultation: the consultation is developed through both a specific setting and a particular relationship, it is inextricably linked to verbal and non-verbal communication skills, and it is directly applicable to daily clinical practice. The consultant's point of view must be "interlocutor oriented", e.g. helping him/her to further explore the rationale for his/her positions, but it must also highlight the critical issues regarding his/her conclusions.

The ethics consultant must have specific multidisciplinary training. The clinical ethics consultation needs specific skills to offer help to the applicant about a choice that generally has implications for the patient's life (Geppert and Shelton 2012; Schildmann et al. 2013). Several field of study offer also a better advantage to the consultant also to organize or open by oneself a clinical ethics service. The international experience shows that a single person, a small group, or the ethics committee of an institution can conduct an ethics consultation (American Society for Bioethics and Humanities 2011). Each of these models has their own potentialities and criticalities. In Italian settings, which are still marked by a lack of experience in institutionalized ethics consultation, the model of the single ethics consultant seems to be preferred for reasons of feasibility and sustainability (Pegoraro et al. 2016). Certainly a single consultant seems to be more facilitated to organize the work and to move between different hospital wards where he/she might be called for a consultation. It is also appropriate that the Healthcare Ethics Consultation be integrated into an Ethics Consultation Service (Agich 2013; La Puma and Toulmin 1989), constituted by a single consultant or a small team in a stable and organized structure (Clinical ethics service).

The ethics consultant should have the following functions: providing the consultations about clinical cases (the consultant with knowledge and training should be available to patients and medical staff to review a case, to offer informed and prudent counsel, and to assist in mediating conflict); supporting the drafting of guidelines of the institutional mission and the allocation criteria; ethical feed-backing about research protocols; systematic collection of ethical deontological documents (journals, books, encyclopedias, commentaries on judgments etc.); linking up with departments and 
ethicists operating on different levels (institutional, regional, national, international); connecting to the ethics committees (these two organizations need each other, they are not identical or interchangeable and their dialectic should be, in most cases, highly productive); planning, organizing and conducting continuous specific ethical training for clinical teams, individual health professionals, administrative organs and committees.

The ethics consultant does not intervene as a mediator, as a defense attorney, as a spiritual consultant or as a psychologist; he/she creates the conditions, he/she leads and helps subjects in taking an ethically sound and possibly shared decision. The consultant has specific knowledge and skills and can be called like any other specialist.

Therefore an ethics consultant could be described as a skilled professional with experience in Clinical Ethics, as single individual consultant and/or member of a clinical ethics service, a sympathetic counselor with knowledge of the aspects concerning biomedical world, clinical setting, healthcare decision and moral reasoning with communication and interpersonal skills.

\section{The experience of the first two editions}

The master is structured in 2 years and the participants must acquire 60 credits: 30 from lectures and 30 from practical activities and stage. The lessons are located in four places: Rome, Varese, Padua and Naples. It is structured in 6 intensive weeks (Mon-Fri) and 5 weekends (Fri-Sat), distributed in those places where the institutions partners are located.

The teachers /trainers are physicians, experts of ethics, bioethicists, philosophers and theologians with different background and experiences. Organizing master in different centers means to offer to the students the opportunity to know different realities and to learn a plurality of methods and approaches related to ethics consultation.

The main topics treated during the first year are the following: outlines of general bioethics; philosophical anthropology; medical anthropology; moral philosophy and ethical theories; moral reasoning and clinical reasoning; nature and aims of medicine; forensic aspects; issues in Bio-Law; health sociology; healthcare organization (management, care systems, the various professional health, risk assessment and management); genetics and molecular biology; biomedical technologies.

After this first section, the topics treated during the first year related to bioethics and clinical ethics are: issues about beginning of life, end of life, clinical research, transplants and ICUs; Counseling; Communication in health; Narrative medicine; Fundamentals of clinical ethics; Nature, purpose and methodologies of bioethics counseling; the services of clinical bioethics and Health Technology Assessment; the CEC in different field of medicine (prenatal neonatology, obstetrics, geriatrics, ICU, chronic-degenerative department; physical and mental department).

The second year is characterized by practical and group activities about the analysis of the clinical cases and a stage for 3-6 months carrying out one of the following two activities: following activities of an Ethics Committee; attending a structure that provides clinical ethics service.

The participants receive a Diploma at the end of the master after a discussion about a clinical case, it must be analyzed as a real clinical case in need of ethics consultation and presented it in front of a commission. 
The first edition of the Master (2011-2012) was attended by 18 people: 9 medical doctors; 4 philosophers; 2 lawyers; 1 nurse; 1 biologist; 1 pharmacist (coming from various parts of Italy).

The second edition of the Master (2013-2014) was attended by 11 people: 6 medical doctors; 3 philosophers; 1 nurse; 1 biologist, coming from various parts of Italy; 1 from Ukraine, 1 from Chile.

After the two editions the most part of participants $(90 \%)$ have been involved as members in ethics committee and four participants have an employment in a Clinical Ethics Services.

\section{Positive and critical points}

The aspects appreciated by the students were: the content of the lectures and the internships; the collaboration and the choral work between different institutions and centers with the possibility both to know different realities and to define a "common model" to face an ethics consultation, precious at this step of development of the clinical ethics in Italy; the possibility of sharing an experience for more days in the same place, useful to create a significant network even after the completion of the Master.

Greater criticalities could be summarized in two points: as first, the different background of the participants and secondly the difficulties to attend hospital departments.

Firstly, different backgrounds of participants showed some difficulties to find a common language during the discussion and ethical analysis of clinical cases. One hypothesis for resolution would be to provide some specific differentiated modules for each category of professionals.

Second criticality concerns that set of difficulties to attend hospital departments. In Italy there is a lack of clinical ethics services activated into a hospital. This condition opens a lot of problems about the opportunity to do experience in ethics consultation and to have mentors to follow students. In particular, the need to engage student reiterates the necessity for the internship and practical tutoring to obtain both clinical and theoretical competencies and to acquire a method to organize an ethics consultation in hospital setting, coming into contact with daily clinical practice (Gligorov et al. 2015).

A last problem concerns the possibility to apply the acquired skills at the end of the Master. About this issue national working group of Clinical Ethics and Healthcare Ethics Consultation is working to offer a possibility to open ethics service in Italian hospitals (Pegoraro et al. 2015).

\section{Conclusions}

Overall results are good and there is a positive feedback about the master and its contents and teaching methods, growing interest on clinical ethics and ethics consultation. Some students began to carry out ethical consultation activity. Future objective is outline much more the professional profile of the ethics consultant to give legal identification at this new professional figure. On April 2016, it has begun the 3rd 
edition of the Master with 12 students, with particular attention to offer more specific internships and to create a network between the students and the national working group of Clinical Ethics and Healthcare Ethics Consultation to improve this new healthcare profession.

\section{References}

Agich, J.G. 2013. Education and the improvement of clinical ethics services. BMC Medical Education 13: 41. Akabayashi, A. (ed.). 2014. The future of bioethics: International dialogues. Oxford: Oxford University Press. American Society for Bioethics and Humanities. 2009. Improving competencies in clinical ethics consultation, an education guide. Glenview, IL: American Society for Bioethics and Humanities, 8.

American Society for Bioethics and Humanities. 2015. improving competencies in clinical ethics consultation, an education guide. Chicago, IL: American Society for Bioethics and Humanities, 2nd ed., 2.

American Society for Bioethics and Humanities, Core Competencies Update Task Force. 2011. Core competencies for health care ethics consultation: a report of the American Society for Bioethics and Humanities. Glenview, IL: American Society for Bioethics and Humanities, 2nd ed., 2.

Aulisio, M.M., M.R. Arnold, and J.S. Younger (eds.). 2003. Ethics consultation. From theory to practice. Baltimore: The JohnHopkins University Press.

Brock, W.D., K.J. Park, and D. Wendler. 2014. Making treatment decisions for oneself: weighing the value. Hastings Center Report 44(2): 22-25.

Dudzinski, D.M., R. Rhodes, and A. Fiester. 2013. Pedagogical goals for academic bioethics programs. Cambridge Quarterly of Healthcare Ethics, Cambridge University Press, 22: 284-296.

Geppert, M.A.C., and N.W. Shelton. 2012. A comparison of general medical and clinical ethics consultations: what can we learn from each other? Mayo Clinic Proceedings 87(4): 381-389.

Gligorov, N., M.T. Sommer, B. Tobin, C. Ellen, E.L. Frank, and R. Rhodes. 2015. Bridging the gap between knowledge and skill: integrating standardized patients into bioethics education. Hastings Center Report 45(5): 25-30.

Gusmano, K. M., V.G. Rodwin, and D. Weisz. 2010. Health care in world cities Baltimore. The Johns Hopkins University Press.

Hurst, S.A., A. Perrier, R. Pegoraro, S. Reiter-Theil, R. Forde, A.M. Slowther, E. Garrett-Mayer, and M. Danis. 2007. Ethical difficulties in clinical practice: experiences of European doctors. Journal of Medical Ethics 33(1): 51-57.

Jennings, B. (ed. in chief). 2014. Bioethics. Michigan: Macmillan Reference USA, 4th ed., vol. II, 596.

Kodish, E., J.J. Fins, I.I.I. Clarence Braddock, F. Cohn, N.N. Dubler, M. Danis, A.R. Derse, R.A. Pearlman, M. Smith, A. Tarzian, S. Youngner, and M.G. Kuczewski. 2013. Quality attestation for clinical ethics consultants: a two-step model from the American Society for Bioethics and Humanities. Hastings Center Report 43(5): 26-36.

La Puma, J., and E.S. Toulmin. 1989. Ethics consultants and ethics committees. Archives of Internal Medicine 149(5): 1109-1112.

Nicoli, F., M. Picozzi, and R. Pegoraro. 2015. Clinical ethics consultation in Italy: a new scenario is expected after the document of Trento. Eacme Newsletter 40: 11-13.

Niebroj, L. 2010. Bioethics of life programs: taking seriously moral pluralism in clinical setting. European Journal of Medical Research 15(II): 98-101.

Orlowski, P.J., S. Hein, J.A. Christensen, R. Meinke, and T. Sincich. 2006. Why doctors use or do not use ethics consultation. Journal of Medical Ethics 32(9): 499-502.

Pegoraro, R., G. Putoto, and E. Wray (eds.). 2007. Hospital based bioethics: A European perspectives. Padova: Piccin.

Pegoraro, R., M. Picozzi, and G. A. Spagnolo. 2015. La consulenza etica in ambito sanitario in Italia. Medicina e Morale n.6.

Pegoraro, R., M. Picozzi, and G.A. Spagnolo. 2016. La Consulenza di Etica Clinica in Italia. Lineamenti e Prospettive. Padova: Piccin.

Pfäfflin, M., K. Kobert, and S. Reiter-theil. 2009. Evaluating clinical ethics consultation: a european perspective. Cambridge Quarterly of Healthcare Ethics Cambridge University Press 18: 406-409.

Racine, E., and K. Hayes. 2006. The need for a clinical ethics service and its goals in a community healthcare service centre: a survey. Journal of Medical Ethics 32(10): 564-566. 
Reich, T.W., M. Picozzi, M. Tavani, and P. Cattorini. (eds.). 2003. Verso una professionalizzazione del bioeticista. Analisi teoriche e ricadute pratiche. Giuffrè Milano, viii-xii, xi-xii.

Schildmann, J., J.-S. Gordon, and J. Vollmann (eds.). 2013. Clinical ethics consultation: Theories and methods, implementation, evaluation. Farnham and Burlington: Ashgate.

Spike, J.P. 2012. Training in clinical ethics consultation: the Washington Hospital Center course. The Journal of Clinical Ethics 23(2): 147-151.

Widdershoven, G., T. Abma, and B. Molewijk. 2009. Empirical ethics as dialogical practice. Bioethics 23: 236-248.

Zaner, M.R. 1999. Performance, talk, reflection, what is going on in clinical ethics consultation. Dordrecht: Kluwer Academic Publisher.

Zonza, M., and P. Refolo. 2014. Documento di Trento. La consulenza etica in ambito sanitario in Italia. Medicina e Morale 1: 121-127. 